\title{
CONCEPTS
}

\section{Heat Stroke Risk for Open-Water Swimmers During Long-Distance Events}

\author{
Filippo Macaluso, PhD; Rosario Barone, PhD; Ashwin W. Isaacs; Felicia Farina, MD; Giuseppe Morici, MD; \\ Valentina Di Felice, PhD \\ From the Department of Experimental Biology and Clinical Neurology, University of Palermo, Palermo, Italy (Drs Macaluso, Barone, Farina, \\ Morici, and Di Felice); and the Department of Physiological Sciences, Stellenbosch University, Stellenbosch, South Africa (Dr Isaacs).
}

\begin{abstract}
Open-water swimming is a rapidly growing sport discipline worldwide, and clinical problems associated with long-distance swimming are now better recognized and managed more effectively. The most prevalent medical risk associated with an open-water swimming event is hypothermia; therefore, the Federation Internationale De Natation (FINA) has instituted 2 rules to reduce this occurrence related to the minimum water temperature and the time taken to complete the race. Another medical risk that is relevant to open-water swimmers is heat stroke, a condition that can easily go unnoticed. The purpose of this review is to shed light on this physiological phenomenon by examining the physiological response of swimmers during long-distance events, to define a maximum water temperature limit for competitions. We conclude that competing in water temperatures exceeding $33^{\circ} \mathrm{C}$ should be avoided.
\end{abstract}

Key words: body composition, water sport, skin temperature, body temperature, triathlon, swimming

\section{Introduction}

The Federation Internationale De Natation (FINA) defines open-water swimming as any competition that takes place in rivers, lakes, oceans, or water channels, and distinguishes between 2 categories on the basis of the distance swum. A long-distance swimming event includes any competition in open water up to a maximum of $10 \mathrm{~km}$, whereas marathon swimming events exceed $10 \mathrm{~km} .{ }^{1}$ There are more than 6500 open-water swimming clinics, camps, tours, races, and events in at least 158 countries globally, in which many elite and recreational athletes compete, followed by masters athletes. ${ }^{2,3}$ This however does not take into account all of the triathlon events in which the first phase of the race is open-water swimming. ${ }^{4}$

Hypothermia is the most prevalent medical risk associated with open-water swimmers during longdistance events. A few recent reviews fully describe the impact of this condition. ${ }^{5,6}$ In an attempt to reduce the frequency of hypothermia, the FINA and ITU

Corresponding author: Filippo Macaluso, $\mathrm{PhD}$, Dipartimento di Biomedicina Sperimentale e Neuroscienze Cliniche, Università di Palermo, Via del Vespro, 129, Palermo, 90127 Italy (e-mail: filippo. macaluso@unipa.it).
(International Triathlon Union) have introduced a set minimum temperature of water in which participants are allowed to compete as well as a time limit in which to complete a specific race (calculated from the finish time of the first swimmers and changed on the basis of the distance swum), because lower water temperatures and prolonged swim duration increase the risk of participants developing hypothermia. ${ }^{7}$ The temperature limit established by FINA and ITU are $16^{\circ} \mathrm{C}$ and $14^{\circ} \mathrm{C}$, respectively; however, according to the ITU rules, a wetsuit is compulsory when water temperatures are below $20^{\circ} \mathrm{C}^{4}$ Interestingly, no rules have been introduced to limit a maximum water temperature at which athletes may not compete. Less is known of the risk of developing heat stroke during open-water swimming. This is significant because this condition has previously resulted in the death of a number of elite athletes; for instance, during the 2010 FINA 10-km open-water World Cup in Fujairah (Dubai), an elite athlete of team USA died. ${ }^{8}$ Although medical details of the autopsy have not been released, concerns have been raised about the water temperature during the swimming competition. FINA officials claim that the water temperature exceeded $31^{\circ} \mathrm{C}$ (near its finish at 11:30 AM). This may have been too high when taking into consideration 
that the maximum water temperature during pool competitions is $28^{\circ} \mathrm{C}$.

Therefore, the purpose of this review is to describe the medical risk associated with heat stroke during openwater swimming events, a condition that can easily go unnoticed. The aim is also to examine the physiological response of swimmers during long-distance swimming events conducted in warm water.

Potential studies were identified by searching electronic databases: PubMed (1950-2012), Cochrane (1898-2012), Scopus (1960-2012), and Google scholar; the final search was conducted in December 2012. The search terms used included both single words and combinations of words: open water, swimming, swimmers, triathlon, and water temperature. Bibliographies were checked, and experts were consulted for any additional studies. Research studies and case reports available as full papers were deemed eligible if they conformed to the predetermined inclusion (adults 16 years and older, both sexes, any sample size, any distance and time swum, any food or liquid ingested, English language, full paper only) and exclusion (any other physical activity conducted in water, pathological conditions, language other than English, abstract-only conference proceedings) criteria.

\section{Heat Stroke}

Heat stroke occurs when the core body temperature rises above $40^{\circ} \mathrm{C}$, and it is caused by the failure of the brain's temperature regulatory center in the hypothalamus. Failure is caused by the inability of the body's system to dissipate heat, inducing a dramatic rise in body temperature. This hyperthermic condition results in death of $20 \%$ of reported cases as a result of heart failure or cerebral edema. ${ }^{9}$ Heat stroke is the second leading cause of exercise-related mortality. Noakes ${ }^{10}$ pointed out that heat stroke can only occur when the athlete's rate of heat production exceeds the rate at which the excess heat produced during exercise can be dissipated into the environment, addressing several factors that may affect the capacity of the environment to absorb the heat generated by the athletes during exercise and a few factors that may increase the risk of developing heat stroke. $^{10,11}$ These factors can be summarized as high environmental temperature; low potential for convective cooling (during land sports: still wind and high humidity conditions); elevated rate of energy expenditure (higher level of exercise intensity); and greater body mass and percentage body fat. One more component of heat stroke is the excessive heat production by abnormal muscle metabolism in subjects with a genetic disorder of the skeletal muscle. ${ }^{12}$

\section{Land-Sports vs Swimming}

Body temperature regulation during exercise on land occurs by dissipating heat via sweat evaporation, a process that does not occur during exercise in water. Moreover, convection and conduction is much greater in the water compared with land-sports, increasing heat loss or gain during physical activity. ${ }^{13}$ Thus, during swimming when the water temperature exceeds the temperature of the skin, swimmers will experience heat gain and a consequent rise in body temperature.

Studies on the thermophysiological response of swimmers have been summarized in the Table, although studies that investigate the thermophysiological response of subjects who perform different physical activities (such as running) in water have been excluded in this review $^{20,21}$ because of the specificity of the swimming motion and its unique physiological responses. ${ }^{3,22}$

From the Table it is evident that during swimming at high intensities $(>50 \%)$, sweat evaporation does not occur in water and convection and conduction induce an increase in heat gain when the water temperature is higher than or similar to skin temperature. ${ }^{14-19}$ In fact, Costill et $\mathrm{al}^{14}$ observed a rise in rectal temperature in swimmers who swam 20 minutes (freestyle) at $27^{\circ} \mathrm{C}$ and $33^{\circ} \mathrm{C}$, whereas skin temperature rose in the $33^{\circ} \mathrm{C}$ trials and decreased in the $17^{\circ} \mathrm{C}$ and $27^{\circ} \mathrm{C}$ trials. These data are in contrast to the study conducted by Fujishima et $a{ }^{18},{ }^{18}$ who observed a rise in skin temperature but not in rectal temperature in swimmers after 120 minutes (breaststroke) at $33^{\circ} \mathrm{C}$. One possible reason that might explain these differences are the different swimming styles used during these studies, although this hypothesis needs explicit testing. Nadel et $\mathrm{al}^{15}$ showed that the core temperature during 20 minutes of swimming increased with the increase of exercise intensity; core body temperature decreased in $18^{\circ} \mathrm{C}$ and $26^{\circ} \mathrm{C}$ water at $40 \%$ maximal oxygen consumption $\left(\mathrm{V}_{2} \max \right)$, and it increased in $26^{\circ} \mathrm{C}$ and $33^{\circ} \mathrm{C}$ water at $70 \%$ of $\dot{\mathrm{V}}_{2} \max$. To our knowledge, we were the only researchers to investigate the thermophysiological response of swimmers during a simulated open-water race $(5 \mathrm{~km})$ in a swimming pool maintained at different water temperatures. ${ }^{19}$ The rectal temperature of swimmers increased in the $27^{\circ} \mathrm{C}$ and $32^{\circ} \mathrm{C}$ trials, although this increase was significantly greater in the $32^{\circ} \mathrm{C}$ trial. ${ }^{19}$

The phenotype of open-water and pool swimmers appears to be different, and these differences may have an advantage in long-distance events in cold water but may increase the risk of developing heat stroke in long-distance events in warm water. Competitive open-water swimmers have been described by VanHeest et $\mathrm{al}^{23}$ as shorter and lighter, with lower muscle mass and more fat mass than 
Table. Changes in body temperature of swimmers at different water temperatures

\begin{tabular}{|c|c|c|c|c|c|}
\hline References & Time/distance & Intensity & Water temperature & Measurement & Body temperature \\
\hline \multirow[t]{6}{*}{ Costill et al ${ }^{14}$} & $20 \mathrm{~min}$ & $50 \%$ & $17^{\circ} \mathrm{C}$ & Rectal & $\Leftrightarrow$ \\
\hline & & & $27^{\circ} \mathrm{C}$ & Rectal & $\Uparrow+0.5^{\circ} \mathrm{C}$ \\
\hline & & & $33^{\circ} \mathrm{C}$ & Rectal & $\Uparrow+0.8^{\circ} \mathrm{C}$ \\
\hline & & & $17^{\circ} \mathrm{C}$ & Skin & $\Downarrow-14^{\circ} \mathrm{C}$ \\
\hline & & & $27^{\circ} \mathrm{C}$ & Skin & $\Downarrow-5^{\circ} \mathrm{C}$ \\
\hline & & & $33^{\circ} \mathrm{C}$ & Skin & $\Uparrow+1^{\circ} \mathrm{C}$ \\
\hline \multirow[t]{5}{*}{ Nadel et al ${ }^{15}$} & $20 \mathrm{~min}$ & $40 \%$ & $18^{\circ}-26^{\circ} \mathrm{C}$ & Core & $\Downarrow-0.5^{\circ} \mathrm{C}$ \\
\hline & & & $33^{\circ} \mathrm{C}$ & Core & $\Uparrow+1^{\circ} \mathrm{C}$ \\
\hline & & $70 \%$ & $18^{\circ} \mathrm{C}$ & Core & $\Downarrow-0.5^{\circ} \mathrm{C}$ \\
\hline & & & $26^{\circ} \mathrm{C}$ & Core & $\Uparrow+0.7^{\circ} \mathrm{C}$ \\
\hline & & & $33^{\circ} \mathrm{C}$ & Core & $\Uparrow+1.5^{\circ} \mathrm{C}$ \\
\hline \multirow[t]{6}{*}{ Holmer and Bergh ${ }^{16}$} & $20 \mathrm{~min}$ & $50 \%$ & $18^{\circ} \mathrm{C}$ & Esophageal & $\Leftrightarrow$ \\
\hline & & & $26^{\circ} \mathrm{C}$ & Esophageal & $\Uparrow+1.0^{\circ} \mathrm{C}$ \\
\hline & & & $34^{\circ} \mathrm{C}$ & Esophageal & $\Uparrow+1.0^{\circ} \mathrm{C}$ \\
\hline & $5-8 \mathrm{~min}$ & Maximal & $18^{\circ} \mathrm{C}$ & Esophageal & $\Leftrightarrow$ \\
\hline & & & $26^{\circ} \mathrm{C}$ & Esophageal & $\Uparrow+0.5^{\circ} \mathrm{C}$ \\
\hline & & & $34^{\circ} \mathrm{C}$ & Esophageal & $\Uparrow+1.0^{\circ} \mathrm{C}$ \\
\hline \multirow[t]{3}{*}{ Galbo et $\mathrm{al}^{17}$} & $60 \mathrm{~min}$ & $68 \%$ & $21^{\circ} \mathrm{C}$ & Rectal & $\Downarrow-0.8^{\circ} \mathrm{C}$ \\
\hline & & & $27^{\circ} \mathrm{C}$ & Rectal & $\Uparrow+0.7^{\circ} \mathrm{C}$ \\
\hline & & & $33^{\circ} \mathrm{C}$ & Rectal & $\Uparrow+1.3^{\circ} \mathrm{C}$ \\
\hline \multirow[t]{5}{*}{ Fujishima et $\mathrm{al}^{18}$} & $120 \mathrm{~min}$ & $50 \%$ & $23^{\circ}-28^{\circ} \mathrm{C}$ & Rectal & $\Downarrow-1^{\circ} \mathrm{C}$ \\
\hline & & & $33^{\circ} \mathrm{C}$ & Rectal & $\Leftrightarrow$ \\
\hline & & & $23^{\circ} \mathrm{C}$ & Skin & $\Downarrow-5^{\circ} \mathrm{C}$ \\
\hline & & & $28^{\circ} \mathrm{C}$ & Skin & $\Downarrow-3.5^{\circ} \mathrm{C}$ \\
\hline & & & $33^{\circ} \mathrm{C}$ & Skin & $\Uparrow+1.5^{\circ} \mathrm{C}$ \\
\hline \multirow[t]{3}{*}{ Macaluso et $\mathrm{al}^{19}$} & $5 \mathrm{~km}$ & Maximal & $23^{\circ} \mathrm{C}$ & Rectal & $\Leftrightarrow$ \\
\hline & & & $27^{\circ} \mathrm{C}$ & Rectal & $\Uparrow+1^{\circ} \mathrm{C}$ \\
\hline & & & $32^{\circ} \mathrm{C}$ & Rectal & $\Uparrow+2{ }^{\circ} \mathrm{C}$ \\
\hline
\end{tabular}

Symbol $\Uparrow$ indicates an increase in body temperature compared with baseline; $\Leftrightarrow$, no changes; $\Downarrow$, decrease.

elite pool swimmers. Moreover, Keatinge et $\mathrm{al}^{24}$ showed that swimmers with more subcutaneous fat were able to endure longer swimming bouts in cold water compared with individuals with lower body fat. A high percentage of body fat, a characteristic much more evident in female and master athletes, may improve buoyancy ${ }^{25}$ and protect against hypothermia, ${ }^{7}$ although this specific phenotype may limit the dissipation of heat into the environment, increasing heat production during swimming and increasing the risk of developing heat stroke during an open-water event performed in warm water.

\section{Conclusions}

The studies reviewed indicate that there is a potential risk of heat stroke for open-water swimmers during long events performed in warm water. Risk factors are attributable to increased exercise intensity, specific body composition of open-water swimmers, and a low potential for convective cooling during swimming. We recognize the need for further studies to determine correlations between body core temperature and both water temperature and performance, especially because it was shown that measuring body core temperature is uncomplicated and practicable and provides reliable data. ${ }^{26,27}$ Moreover, all of the studies cited have been conducted in indoor swimming pools, whereas during open-water events the sunlight may increase heat gain by radiation.

It is difficult to extrapolate a water temperature limit from the literature because no cases have been reported in scientific journals, but in light of the studies summarized in the Table, which demonstrate an increase in body temperature of $1^{\circ} \mathrm{C}$ to $2^{\circ} \mathrm{C}$ in swimmers who train or simulate a race in a swimming pool with water warmer than $32^{\circ} \mathrm{C}$ to $33^{\circ} \mathrm{C}$, we propose the limit of $33^{\circ} \mathrm{C}$ as a possible maximum water temperature for open-water events.

\section{References}

1. FINA. Open water swimming rules. 2012http://www.fina. org/H2O/index.php?option=com_content 
$\&$ view=category $\&$ id=83:open-water-swimming-rules \& Itemid=184\&layout=default. Accessed June 13, 2013.

2. Sharp RL. Swimming. In: Maughan RJ, ed. Nutrition in Sport (Encyclopedia of Sports Medicine). Vol 7. London, UK: Blackwell Science; 2000. 609-620.

3. Sharp RL. Physiology of swimming. In: Garrett WE, Jr Kirkendall DT, eds. Exercise and Sport Science. Philadelphia, PA: Lippincott Williams \& Wilkins; 2000: 895-904.

4. ITU Triathlon rulebook. 2012. Available at: http://www. triathlon.org. Accessed June 13, 2013.

5. Dallam GM, Jonas S, Miller TK. Medical considerations in triathlon competition: recommendations for triathlon organisers, competitors and coaches. Sports Med. 2005;35:143-161.

6. Gerrard DF. Open water swimming. Particular medical problems. Clin Sports Med. 1999;18:337-347, vii.

7. Brannigan D, Rogers IR, Jacobs I, Montgomery A, Williams A, Khangure N. Hypothermia is a significant medical risk of mass participation long-distance open water swimming. Wilderness Environ Med. 2009;20:14-18.

8. http://www.huffingtonpost.com/2010/10/23/fran-crippendead-us-swim_n_772909.html. Accessed June 13, 2013.

9. Brooks GA, Fahey TD, White TP, Baldwin KM. Textbook of Exercise Physiology, Human Bioenergetics and Its Applications. 3rd ed. Mountain View, CA: Mayfield Publishing Company; 2000.

10. Noakes TD. Dehydration during exercise: what are the real dangers? Clin J Sport Med. 1995;5:123-128.

11. Noakes TD. Waterlogged: The Serious Problem of Overhydration in Endurance Sports. Champaign, IL: Human Kinetics; 2012.

12. Rae DE, Knobel GJ, Mann T, Swart J, Tucker R, Noakes TD. Heatstroke during endurance exercise: is there evidence for excessive endothermy? Med Sci Sports Exerc. 2008;40:1193-1204.

13. Nielsen B, Davies CT. Temperature regulation during exercise in water and air. Acta Physiol Scand. 1976;98:500-508.

14. Costill DL, Cahill PJ, Eddy D. Metabolic responses to submaximal exercise in three water temperatures. J Appl Physiol. 1967;22:628-632.

15. Nadel ER, Holmér I, Bergh U, Astrand PO, Stolwijk JA. Energy exchanges of swimming man. J Appl Physiol. 1974;36:465-471.
16. Holmér I, Bergh U. Metabolic and thermal response to swimming in water at varying temperatures. $J$ Appl Physiol. 1974;37:702-705.

17. Galbo H, Houston ME, Christensen NJ, et al. The effect of water temperature on the hormonal response to prolonged swimming. Acta Physiol Scand. 1979;105:326337.

18. Fujishima K, Shimizu T, Ogaki T, et al. Thermoregulatory responses to low-intensity prolonged swimming in water at various temperatures and treadmill walking on land. J Physiol Anthropol Appl Human Sci. 2001;20:199206.

19. Macaluso F, Di Felice V, Boscaino G, et al. Effects of three different water temperatures on dehydration in competitive swimmers. Sci Sports. 2011;26:265-271.

20. McArdle WD, Magel JR, Lesmes GR, Pechar GS, Metabolic and cardiovascular adjustment to work in air and water at 18, 25, and 33 degrees C. J Appl Physiol. 1976;40:85-90.

21. Shimizu T, Kosaka M, Fujishima K. Human thermoregulatory responses during prolonged walking in water at 25, 30 and 35 degrees C. Eur J Appl Physiol Occup Physiol. 1998;78:473-478.

22. Figueiredo P, Barbosa TM, Vilas-Boas JP, Fernandes RJ. Energy cost and body centre of mass' 3D intracycle velocity variation in swimming. Eur J Appl Physiol. 2012; 112:3319-3326.

23. VanHeest JL, Mahoney CE, Herr L. Characteristics of elite open-water swimmers. The J Strength Cond Res. 2004; 18:302-305.

24. Keatinge WR, Khartchenko M, Lando N, Lioutov V. Hypothermia during sports swimming in water below 11 degrees C. Br J Sports Med. 2001;35:352-353.

25. Ama PFM, Ambassa S. Buoyancy of African black and European white males. Am J Hum Biol. 1997;9:87-92.

26. Knechtle B, Christinger N, Kohler G, Knechtle P, Rosemann T. Swimming in ice cold water. Ir J Med Sci. 2009; 178:507-511.

27. Rüst CA, Knechtle B, Rosemann T. Changes in body core and body surface temperatures during prolonged swimming in water of $10^{\circ} \mathrm{C}$ - a case report. Extreme Physiol Med. 2012;1:1-7. 